\title{
Are There Gender-Specific Aspects in Obesity and Metabolic Surgery? Data Analysis from the German Bariatric Surgery Registry
}

\author{
Christine Stroh ${ }^{a, b}$ Rudolf Weiner ${ }^{c}$ Stefanie Wolff ${ }^{d}$ Christian Knoll ${ }^{e}$ Thomas Manger ${ }^{a, b}$, \\ for the Obesity Surgery Working Group and Competence Network Obesity
}

\footnotetext{
${ }^{a}$ Department of General, Abdominal and Pediatric Surgery, SRH Municipal Hospital, Gera,

${ }^{b}$ Institute for Quality Assurance in Surgical Medicine, University Hospital, Magdeburg,

${ }^{c}$ Department of Surgery, Sachsenhausen Hospital, Frankfurt/M.,

${ }^{\mathrm{d}}$ Department of Surgery, University Hospital,

e StatConsult, Magdeburg, Germany
}

Keywords

Bariatric surgery - Gastric banding - Sleeve gastrectomy . Roux-en-Y gastric bypass · Gender-specific aspects

\section{Summary}

Background: Since January 2005, the status of bariatric surgery in Germany has been examined in conjunction with a quality assurance study of the German Bariatric Surgery Registry (GBSR). All data are registered prospectively in cooperation with the Institute for Quality Assurance in Surgical Medicine at the Otto-von-Guericke University Magdeburg, Germany. Methods: Data are registered in an online database. Data collection on obesity and metabolic surgery is voluntary, and was started in 2005. In addition, follow-up data are collected once a year. Results: Since 2005, 8,293 sleeve gastrectomies, 10,330 Roux-en-Y gastric bypass procedures, and 3,741 gastric banding procedures have been performed in Germany, according to the data of the GBSR. Mean age and mean body mass index of female patients with gastric banding, sleeve gastrectomy, or Roux-en-Y gastric bypass were significantly lower than those of male patients. The incidence of relevant comorbidities was significantly higher in male than in female patients. Conclusion: Metabolic and obesity surgery is becoming more and more popular in Germany. Data from the GBSR study show significant differences in preoperative comorbidities and postoperative complication and mortality rates between male and female patients. There is a need for further evaluation of genderspecific aspects to optimize patient selection and reduce specific postoperative complications.
Schlüsselwörter

Adipositaschirurgie und metabolische Chirurgie . Magenband - Sleeve-Gastrektomie .

Roux-en-Y-Magenbypass · Genderspezifische Aspekte

\section{Zusammenfassung}

Hintergrund: Die aktuelle Situation der Adipositaschirurgie und metabolischen Chirurgie wird seit Januar 2005 mithilfe der Qualitätssicherungsstudie für operative Therapie der Adipositas (German Bariatric Surgery Registry (GBSR)) untersucht. Die Daten werden prospektiv in Zusammenarbeit mit dem Institut für Qualitätssicherung in der operativen Medizin der Otto-von-Guericke Universität in Magdeburg, Deutschland, erfasst und analysiert. Methoden: Die Datenerhebung erfolgt mithilfe einer OnlineDatenbank. Auf freiwilliger Grundlage werden alle adipositas- und metabolisch chirurgischen Eingriffe seit 2005 registriert. Zusätzlich zu den Operationsdaten werden die Befunde der jährlichen Nachsorgeuntersuchungen erhoben. Ergebnisse: Seit 2005 wurden den Daten des GBSR zufolge 8293 Sleeve-Gastrektomien, 10330 Roux-en-YMagenbypässe und 3741 Magenband-Operationen durchgeführt. Das mittlere Alter und der mittlere Body-Mass-Index der weiblichen Patientinnen mit Magenband, SleeveGastrektomie und Roux-en-Y-Magenbypass waren signifikant geringer als die der männlichen Patienten. Männer zeigten ebenso eine höhere Inzidenz an Komorbiditäten als Frauen. Schlussfolgerung: Die Zahl der adipositas- und metabolisch chirurgischen Eingriffe steigt in Deutschland stetig an. Die Ergebnisse der Studie des GBSR zeigen signifikante Unterschiede in der genderspezifischen Inzidenz der präoperativen Komorbiditäten, der postoperativen Komplikationen und der Mortalität. Weitere Analysen zu genderspezifischen Aspekten sind erforderlich, um die $\mathrm{Pa}$ tientenselektion in der Adipositaschirurgie zu optimieren und die postoperative Komplikationsrate zu reduzieren. 


\section{Introduction}

Obesity is one of the greatest health-related challenges of the 21st century. According to data of the International Association for the Study of Obesity (IASO), Germany ranks first for prevalence of obesity in both sexes [1]. The German Federal Office of Statistics revealed that in $200951.4 \%$ of the population were overweight or obese. The average body mass index (BMI) of the German population in 2009 was $25.7 \mathrm{~kg} / \mathrm{m}^{2}$, with $60.1 \%$ of men and $42.9 \%$ of women overweight [2]. Life expectancy is markedly shortened by obesity, in particular in young obese persons. The mortality risk rises to between 6and 12 -fold of that of the normal population, with a 12-year reduction in life expectancy for overweight men and 9-year reduction for women. For grade III obesity, a 20-year statistically corroborated reduction in life expectancy has been identified [3]. Surgical measures were compared in studies with conservative treatment. The results of the Swedish Obesity Subject (SOS) Study, which demonstrated the long-term effects of weight reduction on resolution of comorbidities, attest to the marked superiority of surgical treatment measures [4, 5]. Gender-specific aspects have implications for the complication rate, weight reduction, and resolution of comorbidities. The aim of the present study was to compare the data available from the German Bariatric Surgery Registry (GBSR) with international data with regard to gender-specific aspects.

\section{Material and Methods}

The data from the GBSR have been registered prospectively in an online database since January 1, 2005 at the Institute for Quality Assurance in Surgical Medicine of the Otto-von-Guericke University Magdeburg, Germany [6]. This paper evaluates the data on the main performed operations, gastric banding (GB), sleeve gastrectomy (SG), and Roux-en-Y gastric bypass (RYGB), collected between 2005 and 2012, in terms of gender-specific aspects. This study is part of an ongoing multicenter observational study initiated on January 1, 2005 for quality assurance in obesity surgery. All hospitals conducting bariatric surgery in Germany are encouraged to register with the study and enter prospective patient data in an online database. Indication and surgical approach are based on the individual center's clinical practice. Information on the type of surgery (primary or secondary), surgical technique, anthropometric measures, vital and biochemical parameters, comorbidities, and short- and long-term complications is collected at the time of procedure and at annual follow-ups by the individual institutions in a standardized fashion. Short-term complications are classified as: i) intraoperative (injury of the spleen, liver, choledochus or vasculature, pneumothorax, gastric perforation, bleeding, or others), ii) general postoperative (urinary tract infection, renal complications, cardiac events, pulmonary complications, fever, thrombosis, or others), and iii) specific postoperative (bleeding requiring transfusion, bleeding requiring surgical revision, need for gastroscopy, insufficiency of anastomosis, stenosis of anastomoses, mechanical ileus, sepsis, peritonitis, intra-abdominal abscess, wound dehiscence, aseptic wound healing disorder, or others).

To ascertain completeness of data entry, participation in the study is a prerequisite to an institution's certification as a center for bariatric surgery, and reported case numbers are verified against a hospital's clinical and billing documentation. The anonymized data is provided to the insti- tutions, and serves as a center's quality control in regards to surgical indication, complication rates, outcome, and follow-up in comparison with other centers. To optimize the quality and integrity of the registry data (e.g. minimize missing data and ensure adherence to eligibility criteria), statistical plausibility checks are employed, and regular random audits are conducted by the study director.

The study period ranged from January 1, 2005 to December 31, 2012. 137 centers participated. Patients who underwent a primary bariatric procedure in this time period were included in a descriptive statistical analysis performed by an independent statistical consulting firm (StatConsult, Magdeburg, Germany).

All computations were performed using SAS ${ }^{\circledR} 9.2$ (SAS Institute, Cary, NC, USA) with a type 1 error rate of $\mathrm{p}<0.05$. Baseline and individual time-point data were compared by robust t-test for continuous variables (weight, BMI, age), or by chi-square test for nominal data (presence of comorbidities, gender). Intra-subject comparisons of pre- and postoperative data were performed by paired t-test (weight, BMI). Outcomes of surgical procedures were compared by one-way analysis of variance (ANOVA) (weight, BMI).

The study was conducted according to the Recommendations of the Declaration of Helsinki for Biomedical Research and the Guidelines and Standards of the Institutional Review Boards. All patients provided informed consent prior to entering the study. Aspects studied included demographic data, surgical parameters, complications, mortality, weight loss, and amelioration of comorbidities following GB, SG, and RYGB with respect to incidence in men and women. A comparison of the results with the literature was performed.

\section{Results}

The numbers of GB, SG, and RYGB as well as the gender distribution are illustrated in figure 1.

\section{Demographic Data}

With regard to gender distribution for bariatric procedures, and in particular for GB, SG, and RYGB, the proportion of women was higher. The mean age of women compared to that of men was significantly lower for all procedures. Female patients had a significantly lower BMI. Table 1 shows the demographic data for all GB, SG, and RYGB patients as well as those comparing men and women. Figures 2 and 3 show the distribution of age and BMI for patients in relation to the three bariatric procedures.

\section{Comorbidities}

Comorbidities were recorded for all patients. Patients with SG and RYGB had a greater number of comorbidities than all other patients undergoing obesity surgery and registered in the GBSR. In the entire study, $79.5 \%$ of patients with GB, $89.9 \%$ of patients with SG, and $86.7 \%$ of patients with RYGB suffered from comorbidities. The percentage of comorbidities in men compared to women was higher if SG or RYGB were performed. Independent of the type of operation, male patients generally had a significantly higher incidence of hypertension, non-insulin-dependent diabetes mellitus type II (NIDDM), and sleep apnea. Incidence of hypertension was $59.4 \%$ in male GB patients, $73.1 \%$ in male SG patients, and $69.6 \%$ in male RYGB 
Fig. 1. Gender-related distribution of GB, SG, and RYGB.

Fig. 2. Distribution of age (years) in patients with GB, SG, and RYGB.
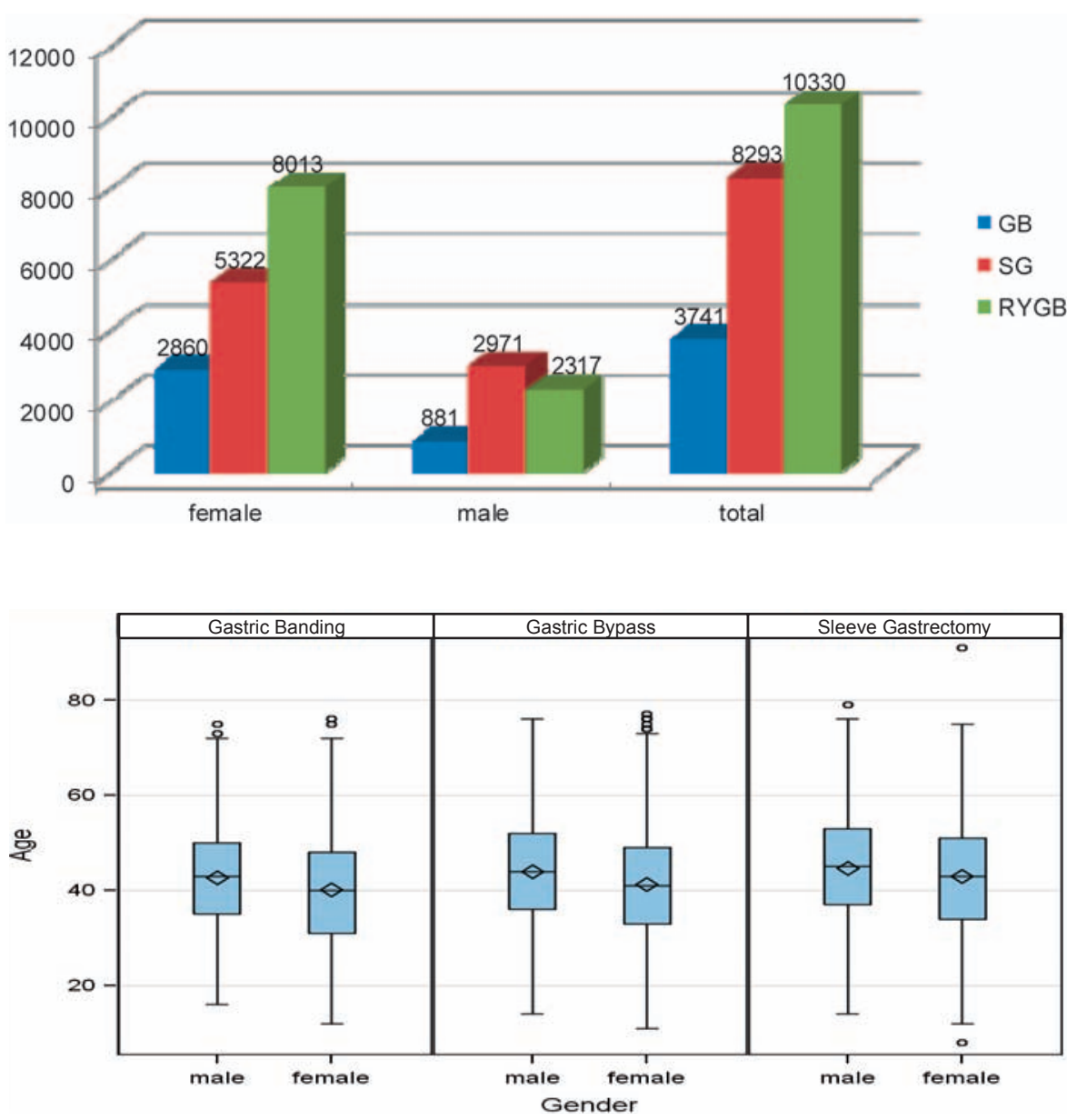

Table 1. Demographic data - mean age and BMI

\begin{tabular}{llll}
\hline Operation & \multicolumn{2}{l}{ Sex } & $\mathrm{p}$ \\
\cline { 2 - 3 } & female & male & \\
\hline Gastric banding & & & \\
$\quad$ Patients, $\mathrm{n}$ & 2,860 & 881 & $<0.001$ \\
$\quad$ Mean age, years & 40.1 & 42.6 & $<0.001$ \\
$\quad$ Mean BMI, kg/m & 44.8 & 46.4 & $<0.001$ \\
Sleeve gastrectomy & & & \\
$\quad$ Patients, $\mathrm{n}$ & 5,322 & 2,971 & $<0.001$ \\
$\quad$ Mean age, years & 42.9 & 44.7 & $<0.001$ \\
$\quad$ Mean BMI, kg/m & 51.6 & 53.1 & $<0.001$ \\
Roux-en-Y gastric bypass & & & \\
$\quad$ Patients, $\mathrm{n}$ & 8,013 & 2,317 & $<0.001$ \\
$\quad$ Mean age, years & 41.3 & 43.9 & $<0.001$ \\
$\quad$ Mean BMI, kg/m ${ }^{2}$ & 48.1 & 48.6 & $<0.001$ \\
\hline
\end{tabular}

patients. For insulin-dependent diabetes mellitus type II (IDDM), female patients had a significantly lower incidence than male patients, with 4.6 versus $8.9 \%$ for GB, 11.1 versus $17.9 \%$ for $\mathrm{SG}$, and 9.1 versus $17.3 \%$ for RYGB. The prevalence of sleep apnea in female and male patients was 8.6 versus $25.5 \%(\mathrm{p}<0.001)$ with $\mathrm{GB}, 19.1$ versus $39.8 \%(\mathrm{p}<0.001)$ with SG, and 14.6 versus $37.1 \%(\mathrm{p}<0.001)$ with RYGB. No signifi- cant gender-specific differences were detected for the occurrence of skeletal diseases and pulmonary embolism. The gender-specific proportions of comorbidities are given in table 2 .

\section{Data on Surgical Technique}

Since 2005, data have been recorded for GB and RYGB, and since 2006 for SG. GB is currently performed in 45, SG in 93, and RYGB in 85 of the participating hospitals. More than $98 \%$ of all primary bariatric procedures were performed using laparoscopy. No gender-specific differences were noted in terms of the access route. Clinically not relevant was the 8-min significantly longer operation time for male patients $(\mathrm{p}<0.001)$.

\section{General Postoperative Complication Rates}

The overall general complication rate for GB was $1.66 \%$ ( $\mathrm{n}=$ 62) with a gender-specific difference. Male patients developed more general complications than females. This included cardiac complications and fever lasting longer than 2 days. The overall general postoperative complication rate for patients with SG was $6.10 \%(n=506)$ without any gender-specific difference. Besides urinary infection, there was no significant difference in the general postoperative complication rate between men and women (table 3). Patients with RYGB developed significantly more complications than patients with GB $(\mathrm{p}<0.001)$. The gen- 
Fig. 3. Distribution of $B M I\left(\mathrm{~kg} / \mathrm{m}^{2}\right)$ in patients with GB, SG, and RYGB.

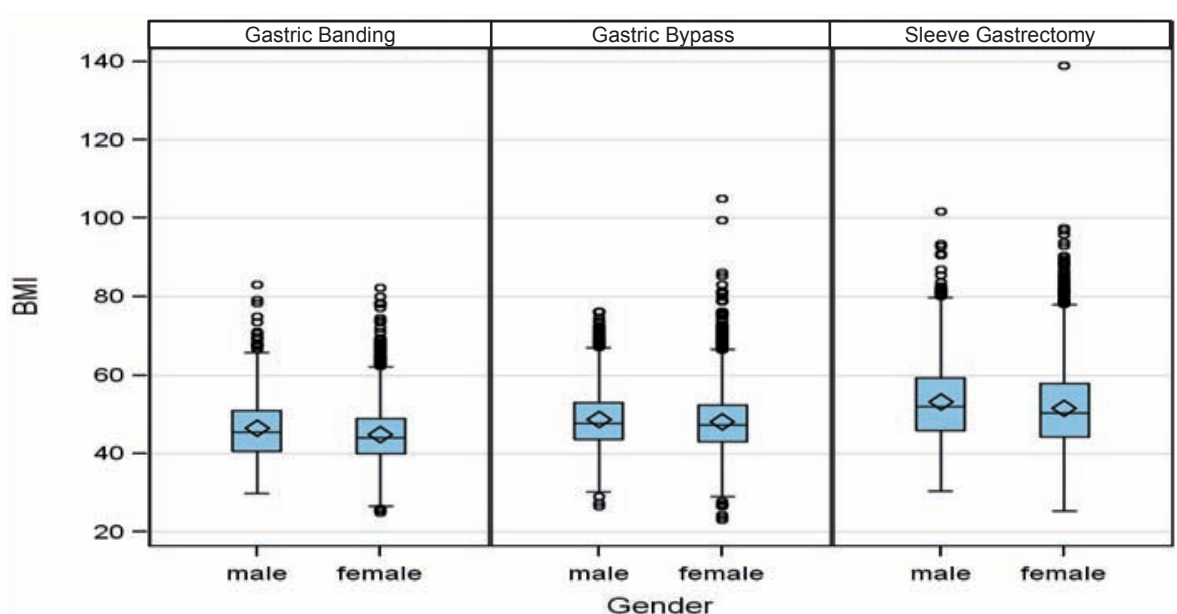

Table 2. Gender-specific distribution of comorbidities

\begin{tabular}{|c|c|c|c|}
\hline \multirow[t]{2}{*}{ Comorbidities } & \multicolumn{2}{|l|}{ Sex, \% } & \multirow[t]{2}{*}{$\mathrm{p}$} \\
\hline & female & male & \\
\hline \multicolumn{4}{|l|}{ None } \\
\hline Gastric banding & 21.6 & 17.8 & 0.002 \\
\hline Sleeve gastrectomy & 11.3 & 8.4 & $<0.001$ \\
\hline Roux-en-Y gastric bypass & 14.5 & 9.3 & $<0.001$ \\
\hline \multicolumn{4}{|l|}{ Hypertension } \\
\hline Gastric banding & 44.0 & 59.4 & $<0,001$ \\
\hline Sleeve gastrectomy & 60.8 & 73.1 & $<0.001$ \\
\hline Roux-en-Y gastric bypass & 54.2 & 69.6 & $<0.001$ \\
\hline \multicolumn{4}{|l|}{ IDDM } \\
\hline Gastric banding & 4.6 & 8.9 & $<0.001$ \\
\hline Sleeve gastrectomy & 11.1 & 17.9 & $<0.001$ \\
\hline Roux-en-Y gastric bypass & 9.1 & 17.3 & $<0.001$ \\
\hline \multicolumn{4}{|l|}{ NIDDM } \\
\hline Gastric banding & 11.5 & 16.9 & $<0.001$ \\
\hline Sleeve gastrectomy & 21.1 & 23.5 & 0.013 \\
\hline Roux-en-Y gastric bypass & 21.3 & 26.3 & $<0.001$ \\
\hline \multicolumn{4}{|l|}{ Pulmonary comorbidity } \\
\hline Gastric banding & 12.7 & 16.0 & $<0.001$ \\
\hline Sleeve gastrectomy & 20.4 & 22.1 & 0.074 \\
\hline Roux-en-Y gastric bypass & 18.2 & 18.7 & 0.548 \\
\hline \multicolumn{4}{|l|}{ Pulmonary embolism } \\
\hline Gastric banding & 1.1 & 1.2 & 0.964 \\
\hline Sleeve gastrectomy & 1.1 & 1.1 & 0.895 \\
\hline Roux-en-Y gastric bypass & 0.5 & 0.8 & 0.120 \\
\hline \multicolumn{4}{|l|}{ Sleep apnea } \\
\hline Gastric banding & 8.6 & 25.5 & $<0.001$ \\
\hline Sleeve gastrectomy & 19.1 & 39.8 & $<0.001$ \\
\hline Roux-en-Y gastric bypass & 14.6 & 37.1 & $<0.001$ \\
\hline \multicolumn{4}{|l|}{ Skeletal disease } \\
\hline Gastric banding & 42.9 & 42.0 & 0.648 \\
\hline Sleeve gastrectomy & 49.1 & 46.1 & 0.008 \\
\hline Roux-en-Y gastric bypass & 40.5 & 39.8 & 0.583 \\
\hline
\end{tabular}

eral postoperative complication rate was significantly higher for male $(7.12 \% ; \mathrm{n}=165)$ than for female $(5.29 \% ; \mathrm{n}=424)$ patients. Male patients developed significantly more cardiac and pulmonary complications than females (table 3 ).
Table 3. Incidence of general postoperative complications

\begin{tabular}{|c|c|c|c|}
\hline \multirow[t]{2}{*}{ Complications } & \multicolumn{2}{|l|}{ Sex } & \multirow[t]{2}{*}{$\mathrm{p}$} \\
\hline & female & male & \\
\hline \multicolumn{4}{|l|}{ Gastric banding } \\
\hline Patients, $\mathrm{n}$ & 2,860 & 881 & $<0.001$ \\
\hline Cardiac, \% & 0.03 & 0.34 & 0.043 \\
\hline Pulmonary, \% & 0.23 & 0.21 & 1.000 \\
\hline Urinary infection, \% & 0.07 & 0.0 & 1.000 \\
\hline Fever, \% & 0.14 & 0.57 & 0.038 \\
\hline Thromboembolism, \% & 0.07 & 0.00 & 1.000 \\
\hline Total, \% & 1.40 & 2.50 & 0.034 \\
\hline \multicolumn{4}{|l|}{ Sleeve gastrectomy } \\
\hline Patients, $\mathrm{n}$ & 5,322 & 2,971 & $<0.001$ \\
\hline Cardiac, \% & 0.43 & 0.71 & 0.115 \\
\hline Pulmonary, \% & 1.09 & 1.21 & 0.665 \\
\hline Urinary infection, \% & 1.39 & 0.50 & $<0.001$ \\
\hline Fever, \% & 1.45 & 1.99 & 0.071 \\
\hline Thromboembolism, \% & 0.08 & 0.10 & 0.707 \\
\hline Total, \% & 5.99 & 6.29 & 0.599 \\
\hline \multicolumn{4}{|l|}{ Roux-en-Y gastric bypass } \\
\hline Patients, $\mathrm{n}$ & 8,013 & 2,317 & $<0.001$ \\
\hline Cardiac, \% & 0.36 & 0.91 & 0.002 \\
\hline Pulmonary, \% & 0.95 & 1.51 & 0.029 \\
\hline Urinary infection, \% & 0.96 & 0.47 & 0.028 \\
\hline Fever, \% & 1.55 & 2.16 & 0.054 \\
\hline Thromboembolism, \% & 0.04 & 0.09 & 0.219 \\
\hline Total, \% & 5.29 & 7.12 & 0.001 \\
\hline
\end{tabular}

\section{Specific Severe Postoperative Complications}

As specific severe complications, leakage or gastric perforation, bleeding, wound infection, and stenosis were considered. Special complications occurred in 43 out of 3,741 $(1.15 \%)$ patients with GB. There was no gender-specific difference in the special complication rate $(p=0.101)$ (table 4). The incidence of postoperative severe complications after SG was $4.87 \%(n=404)$. A gender-specific aspect was detected for the incidence of bleeding necessitating reoperation, leakage, as well as sepsis and peritonitis. For RYGB, the overall specific complication rate was $5.30 \%$. Specific complications 
Table 4. Gender-specific postoperative complications

\begin{tabular}{lllr}
\hline Complications & \multicolumn{2}{l}{ Sex } & \multirow{2}{l}{$\mathrm{p}$} \\
\cline { 2 - 3 } & female & male & \\
\hline Gastric banding & & & \\
$\quad$ Patients, n & 2,860 & 881 & $<0.001$ \\
Intraoperative bleeding, \% & 0.00 & 0.23 & 0.055 \\
Leakage, \% & 0.07 & 0.11 & 0.553 \\
Stenosis, \% & 0.17 & 0.11 & 1.000 \\
Ileus, \% & 0.07 & 0.23 & 0.237 \\
Sepsis, \% & 0.03 & 0.11 & 0.416 \\
Peritonitis, \% & 0.07 & 0.34 & 0.089 \\
Wound infection, \% & 0.42 & 0.68 & 0.401 \\
Total, \% & 0.98 & 1.70 & 0.101 \\
Sleeve gastrectomy & & & \\
Patients, n & 5,322 & 2,971 & $<0.001$ \\
Intraoperative bleeding, \% & 1.11 & 1.72 & 0.027 \\
Leakage, \% & 1.50 & 2.12 & 0.043 \\
Stenosis, \% & 0.17 & 0.07 & 0.347 \\
Ileus, \% & 0.10 & 0.04 & 0.357 \\
Sepsis, \% & 0.91 & 0.49 & 0.030 \\
Peritonitis, \% & 0.98 & 0.45 & 0.006 \\
Wound infection, \% & 0.81 & 0.92 & 0.626 \\
Total, \% & 5.35 & 4.60 & 0.136 \\
Roux-en-Y gastric bypass & & & \\
Patients, n & 8,013 & 2,317 & $<0.001$ \\
Intraoperative bleeding, \% & 0.62 & 0.99 & 0.067 \\
Leakage, \% & 1.68 & 2.37 & 0.035 \\
Stenosis, \% & 0.59 & 0.73 & 0.452 \\
Ileus, \% & 0.30 & 0.49 & 0.290 \\
Sepsis, \% & 0.82 & 0.41 & 0.019 \\
Peritonitis, \% & 1.04 & 0.70 & 0.107 \\
Wound infection, \% & 0.99 & 1.01 & 1.000 \\
Total, \% & 6.34 & 4.99 & 0.011 \\
\hline & & & \\
\hline & & \\
\hline
\end{tabular}

occurred in 547 out of 10,331 patients. The specific complication rate was significantly higher in men $(6.34 \%, \mathrm{n}=147)$ than in women $(4.99 \%, n=400)(p=0.0011)$. Significant differences were detected for leakage or insufficiency of gastrojejunal anastomosis, sepsis, and peritonitis (table 4).

\section{Mortality}

Between January 1, 2005 and December 31, 2012, no patient died following primary GB. However, the mortality rate was $0.35 \%(n=29)$ for SG and $0.27 \%(n=28)$ for RYGB. For $\mathrm{SG}$ and RYGB, we found a higher mortality rate for men than for women (table 5).

\section{Follow-Up Data on Weight Reduction and Amelioration of Comorbidities}

The mean BMI reduction for patients with GB 3 years after operation was $10.9 \mathrm{~kg} / \mathrm{m}^{2}$. The comparison between men and women showed a slightly higher mean BMI reduction for the female population, but the result was not statistically significant. Male patients were able to reduce their mean BMI from $49.0 \mathrm{~kg} / \mathrm{m}^{2}$ to $37.2 \mathrm{~kg} / \mathrm{m}^{2}\left(-11.8 \mathrm{~kg} / \mathrm{m}^{2}\right)$, and female pa-
Table 5. Mortality rates

\begin{tabular}{lccc}
\hline & $\begin{array}{l}\text { Operations, } \\
\mathrm{n}\end{array}$ & $\begin{array}{l}\text { Mortality, } \\
\mathrm{n}(\%)\end{array}$ & $\mathrm{p}$ \\
\hline $\begin{array}{l}\text { Gastric banding } \\
\quad \text { Men }\end{array}$ & 881 & $0(0)$ & \\
$\quad$ Women & 2,860 & $0(0)$ & \\
$\begin{array}{l}\text { Sleeve gastrectomy } \\
\quad\end{array}$ & & \\
$\quad$ Men & 2,971 & $20(0.68)$ & \\
$\quad$ Women & 5,322 & $9(0.17)$ & \\
Roux-en-Y gastric & & & \\
$\quad$ bypass & & & \\
$\quad \begin{array}{l}\text { Men } \\
\text { Women }\end{array}$ & 2,317 & $14(0.61)$ & \\
\hline
\end{tabular}

Table 6. Mean reduction in BMI from time of surgery to last follow-up based on procedure

\begin{tabular}{lcl}
\hline & \multicolumn{2}{l}{ Sex } \\
& female & male \\
\hline Gastric banding & & \\
Patients, $\mathrm{n}$ & 122 & 40 \\
Mean BMI at operation, $\mathrm{kg} / \mathrm{m}^{2}$ & 45.6 & 49.0 \\
Mean BMI 1 year postoperative, $\mathrm{kg} / \mathrm{m}^{2}$ & 38.4 & 40.9 \\
Mean BMI 3 years postoperative, $\mathrm{kg} / \mathrm{m}^{2}$ & 35.0 & 37.2 \\
Sleeve gastrectomy & & \\
Patients, $\mathrm{n}$ & 214 & 65 \\
Mean BMI at operation, $\mathrm{kg} / \mathrm{m}^{2}$ & 49.0 & 50.2 \\
Mean BMI 1 year postoperative, $\mathrm{kg} / \mathrm{m}^{2}$ & 35.6 & 37.3 \\
Mean BMI 3 years postoperative, $\mathrm{kg} / \mathrm{m}^{2}$ & 32.7 & 35.1 \\
Roux-en-Y gastric bypass & & \\
Patients, $\mathrm{n}$ & 105 & 66 \\
Mean BMI at operation, $\mathrm{kg} / \mathrm{m}^{2}$ & 52.5 & 53.5 \\
Mean BMI 1 year postoperative, $\mathrm{kg} / \mathrm{m}^{2}$ & 38.4 & 39.4 \\
Mean BMI 3 years postoperative, $\mathrm{kg} / \mathrm{m}^{2}$ & 36.4 & 37.7 \\
\hline
\end{tabular}

tients from $45.6 \mathrm{~kg} / \mathrm{m}^{2}$ to $35.0 \mathrm{~kg} / \mathrm{m}^{2}\left(-10.6 \mathrm{~kg} / \mathrm{m}^{2}\right)$ (table 6). For patients with SG, the mean BMI reduction 3 years after operation was $15.1 \mathrm{~kg} / \mathrm{m}^{2}$ in male patients. This was slightly less than in female patients $\left(16.1 \mathrm{~kg} / \mathrm{m}^{2}\right)$, without any statistical significance (table 6). Within 3 years of RYGB, male patients lost $15.8 \mathrm{~kg} / \mathrm{m}^{2}$ and female patients $16.1 \mathrm{~kg} / \mathrm{m}^{2}$ (table 6 ). Amelioration rates for IDDM, NIDDM, hypertension, and sleep apnea after GB, SG, and RYGB are shown in table 7.

\section{Discussion}

Since January 1, 2005, primary and revision bariatric procedures have been recorded within the framework of the GBSR by the Institute for Quality Assurance in Surgical Medicine at the Otto-von-Guericke University Magdeburg, with the aim of improving quality of care [6].

$\mathrm{GB}$ is still one of the most frequently performed bariatric operations worldwide, constituting about $17.1 \%$ of all bariat- 
Table 7. Gender-specific amelioration rates of comorbidities after GB, SG, and RYGB

\begin{tabular}{|c|c|c|}
\hline & \multicolumn{2}{|l|}{ Sex, \% } \\
\hline & female & male \\
\hline \multicolumn{3}{|l|}{ Gastric banding } \\
\hline \multicolumn{3}{|l|}{ IDDM } \\
\hline Remission & 59.1 & 60.7 \\
\hline Increase & 12.5 & 12.5 \\
\hline Without change & 28.4 & 26.8 \\
\hline \multicolumn{3}{|l|}{ NIDDM } \\
\hline Remission & 68.9 & 58.6 \\
\hline Increase & 3.4 & 2.0 \\
\hline Without change & 27.6 & 39.4 \\
\hline \multicolumn{3}{|l|}{ Hypertension } \\
\hline Remission & 53.6 & 45.6 \\
\hline Increase & 5.0 & 4.2 \\
\hline Without change & 41.4 & 50.2 \\
\hline \multicolumn{3}{|l|}{ Sleep apnea } \\
\hline Remission & 62.0 & 50.9 \\
\hline Increase & 3.1 & 4.5 \\
\hline Without change & 34.8 & 44.5 \\
\hline \multicolumn{3}{|l|}{ Sleeve gastrectomy } \\
\hline \multicolumn{3}{|l|}{ IDDM } \\
\hline Remission & 76.9 & 76.0 \\
\hline Increase & 7.4 & 8.5 \\
\hline Without change & 15.7 & 15.5 \\
\hline \multicolumn{3}{|l|}{ NIDDM } \\
\hline Remission & 78.9 & 76.8 \\
\hline Increase & 4.7 & 7.3 \\
\hline Without change & 16.4 & 15.8 \\
\hline \multicolumn{3}{|l|}{ Hypertension } \\
\hline Remission & 63.0 & 63.1 \\
\hline Increase & 2.8 & 2.7 \\
\hline Without change & 34.1 & 34.2 \\
\hline \multicolumn{3}{|l|}{ Sleep apnea } \\
\hline Remission & 67.5 & 66.7 \\
\hline Increase & 5.5 & 4.4 \\
\hline Without change & 27.0 & 28.8 \\
\hline \multicolumn{3}{|l|}{ Roux-en-Y gastric bypass } \\
\hline \multicolumn{3}{|l|}{ IDDM } \\
\hline Remission & 81.2 & 83.1 \\
\hline Increase & 10.3 & 7.4 \\
\hline Without change & 8.4 & 9.5 \\
\hline \multicolumn{3}{|l|}{ NIDDM } \\
\hline Remission & 87.1 & 82.6 \\
\hline Increase & 5.8 & 7.5 \\
\hline Without change & 7.1 & 9.9 \\
\hline \multicolumn{3}{|l|}{ Hypertension } \\
\hline Remission & 74.0 & 73.2 \\
\hline Increase & 3.5 & 3.4 \\
\hline Without change & 22.4 & 23.4 \\
\hline \multicolumn{3}{|l|}{ Sleep apnea } \\
\hline Remission & 74.9 & 72.2 \\
\hline Increase & 3.6 & 3.9 \\
\hline Without change & 21.5 & 23.9 \\
\hline
\end{tabular}

ric procedures. Due to the experience with GB and the longterm effects, the operation rate in Europe and across the world has decreased [7]. In Germany, the number of GB procedures has decreased rapidly since 2005. Important reasons for this are the high BMI (overall mean BMI $49.9 \mathrm{~kg} / \mathrm{m}^{2}$ ) and incidence of comorbidities in bariatric surgery patients in Germany. Less than $12 \%$ of all patients in Germany are free from comorbidities. In a literature review comparing GB, RYGB, and SG, the complication rate was $12.1 \%$ for $\mathrm{SG}$, $9.5 \%$ for RYGB, and $6.5 \%$ for GB [8]. Long-term effects of GB have been reported in a systematic review which showed that 15 years after GB an almost $50 \%$ reduction in excess weight was maintained [9]. This review and the included reports did not contain information on gender-specific aspects of weight loss, amelioration of comorbidities, and reoperation rate. However, GB is a safe and less invasive technique showing no difference in long-term results when compared with RYGB [9]. There are no studies with follow-up data for more than 5 years concerned with gender-specific aspects after GB.

SG gained high popularity in Germany. Worldwide, 27.6\% of all bariatric operations performed in 2011 were SGs [7]. This operation not only leads to a restriction of food intake but, due to resection of the fundus, also to less ghrelin production and hence a reduced feeling of hunger. In the bariatric treatment concept, SG is an effective procedure. It was first used as a first-stage procedure in high-risk patients in preparation for duodenal switch, and for patients with a BMI of more than $60 \mathrm{~kg} / \mathrm{m}^{2}$ [10]. However, SG is being increasingly performed as a stand-alone obesity surgery, especially as an alternative to RYGB [7, 11, 12]. However, there are only few studies with long-term follow-up data for more than 5 years [13-15]. To evaluate other factors influencing complications secondary to SG, data from the GBSR were analyzed in regard to gender-specific aspects. We evaluated a higher specific complication rate, especially for bleeding necessitating reoperation, leakage, and sepsis and peritonitis for male patients, as well as a significantly higher mortality rate. Because of their higher BMI and significantly higher incidence of comorbidities, men have a significantly higher overall complication rate and mortality. Therefore, in particular for men aged over 45 years, with a BMI above $55 \mathrm{~kg} / \mathrm{m}^{2}$, hypertension, and/or sleep apnea, the indication for bridging through implantation of a balloon system should be investigated before resorting to SG [16].

GBSR data for gender-specific aspects of RYGB have shown a significant difference for anastomotic insufficiency of gastroenteroanastomosis. The leakage rate for men was $2.37 \%(55 / 2,317)$ and for women $1.68 \%(135 / 8,013)$. Studies with multivariate analysis for RYGB revealed a higher mortality rate for patients with the following characteristics: male gender (odds ratio (OR) 2.80), BMI > $50 \mathrm{~kg} / \mathrm{m}^{2}$ (OR 3.60), hypertension (OR 2.78), pulmonary embolism (OR 2.62), and age above 45 years (OR 1.64) [17]. Because of the abdominal obesity prevalent in men, the operation often poses a techni- 
cal challenge. This is due to the narrow intra-abdominal space. Further studies focusing on hand-assisted laparoscopic RYGB showed that the higher incidence of comorbidities in male patients is not associated with higher perioperative morbidity and mortality rates [18].

The protective effect of the female gender on the complication and mortality rate has been discussed since 2005. Currently, little attention is paid to gender-specific aspects for indication and selection of the surgical technique, especially in obesity and metabolic surgery $[16,19,20]$. The present evaluation shows that men undergoing GB, SG, and RYGB in Germany have a significantly higher BMI than women. Furthermore, it has been shown that decisive changes occurring in inflammatory parameters of male patients are correlated with increased morbidity [21]. An important aspect in the discussion and evaluation of risk parameters is the presence of comorbidities. The findings of the GBSR show that men have significantly more comorbidities than women. Compared with female patients, male patients undergoing GB, SG, and RYGB have a significantly higher incidence of hypertension, IDDM, and sleep apnea. The higher incidence of preoperative comorbidities in men results in a lower remission rate of hypertension, sleep apnea, and NIDDM. Data also show that male patients have to lose significantly more weight than female patients to reach a total remission of hypertension and sleep apnea (not so for diabetes). These results indicate that further discussion is needed about whether GB should be the procedure of choice in male patients with hypertension, diabetes mellitus type II, and sleep apnea. A bias exists in the data of the GBSR in that the onset and duration of the comorbidities have not been evaluated, with the further problem of the low number of patients with follow-up data.

A meta-analysis demonstrated that with a female proportion of $85 \%$ for all obesity surgeries, the 30 -day mortality was $0.1 \%$ for women vs. $4.7 \%$ for men $(\mathrm{p}<0.001)$ [15]. The data of the GBSR also shows a significantly higher mortality rate for men than for women after SG and RYGB. Several factors have been proposed to explain the increased morbidity and mortality in male patients. As a further bias of the GBSR, we ought to highlight that with respect to mortality the learning effect is dependent on volume [22]. To obtain evidence-based data on mortality, there is therefore a need for propensity score analyses of the same patient collective with regard to BMI, comorbidities, and operating time.

\section{Conclusion}

Based on the data of the GBSR study, it was possible to demonstrate that female gender has a protective effect against complications. Because of their higher BMI and significantly higher incidence of comorbidities, men have a significantly higher overall complication rate and mortality. There are no studies with follow-up data for more than 5 years regarding gender-specific aspects after the different bariatric operations. The aim of the GBSR is to evaluate these data and compare GB, SG, and RYGB over a time period of at least 10 years.

\section{Acknowledgement}

We thank all hospitals participating in the study for their active engagement.

\section{Disclosure Statement}

The German Nationwide Survey on Bariatric Surgery is supported by the German Ministry of Research and Education Germany (BMBF), grant number 01GI1124. The responsible investigator is Christine Stroh. There is no conflict of interest. Christine Stroh, Rudolf Weiner, Stefanie Wolff, Christian Knoll, and Thomas Manger confirm that there are no links to the firm whose products are mentioned in the article or to a firm marketing a competing product. The topic is presented in an independent light, and the information outlined is product-neutral. The following firms support the GBSR without any relation to their products: Johnson and Johnson MEDICAL GmbH, Ethicon Endo-Surgery Deutschland (Norderstedt), Covidien Deutschland GmbH (Neustadt/Donau).

\section{References}

1 Lampert T: Übergewicht und Adipositas in Deutschland. RKI Epidemiologisches Bulletin 2007;18:155-156.

2 Statistisches Bundesamt: Mikrozensus - Fragen zur Gesundheit - Körpermaße der Bevölkerung 2009 Wiesbaden, Statistisches Bundesamt, Selbstverlag, 2010.

$\checkmark 3$ Fontaine KR, Redden DT, Wang C, Westfall AO, Allison DB: Years of life lost due to obesity. JAMA 2003;289:187-193.

4 Sjoström L, Lindroos AK, Peltonen M; Swedish Obese Subjects Study Group: Lifestyle, diabetes and cardiovascular risk factors 10 years after bariatric surgery. NEJM 2004;351:2683-2693.

$\checkmark 5$ Sjöström L, Narbro K, Sjöström CD, et al: Effects of bariatric surgery on mortality in Swedish obese subjects. NEJM 2007:357:741-752.
6 Stroh C, Weiner R, Horbach T, Ludwig K, Dressler M, Lippert H, Wolff S, Büsing M, Schmidt U, Manger T; Kompetenznetz Adipositas, Arbeitsgruppe Adipositaschirurgie: New data on quality assurance in bariatric surgery in Germany (article in German). Zentralbl Chir 2013;138:180-188.

7 Buchwald H, Oien DM: Metabolic/bariatric surgery worldwide 2011. Obes Surg 2013;23:427-436.

8 Shi X, Karmali S, Sharma AM, Birch DW: A review of laparoscopic sleeve gastrectomy for morbid obesity. Obes Surg 2010;20:1171-1177.

9 O'Brien PE, Macdonald L, Anderson M: Longterm outcomes after bariatric surgery: fifteen-year follow-up of adjustable gastric banding and a systematic review of the bariatric surgical literature. Ann Surg 2013;257:87-94
10 Gagner M, Boza C: Laparoscopic duodenal switch for morbid obesity. Expert Rev Med Devices 2006; 3:105-112.

11 Stroh C, Birk D, Flade-Kuthe R, et al; Bariatric Surgery Working Group: A nationwide survey on bariatric surgery in Germany - results 2005-2007. Obes Surg 2009;19:105-112.

12 Hüttl TP, Obeidat FW, Parhofer KG, Zügel N, Hüttl PE, Jauch KW, Lang RA: Operative techniques and outcomes in metabolic surgery: sleeve gastrectomy. Zentralbl Chir 2009;134:24-31.

13 Himpens J, Dobbeleir J, Peeters G: Long-term results of laparoscopic sleeve gastrectomy for obesity. Ann Surg 2010;252:319-324. 
14 Weiner RA, Weiner S, Pomhoff I, Jacobi C, Makarewicz W, Weigand G: Laparoscopic sleeve gastrectomy - influence of sleeve size and resected gastric volume. Obes Surg 2007;17:1297-1305.

15 Buchwald H, Estok R, Fahrbach K, Banel D, Sledge I: Trends in mortality in bariatric surgery: a systematic review and meta-analysis. Surgery 2007;142:621-632; discussion 632-635.

16 Stroh C, Köckerling F, Weiner R, Horbach T, Ludwig K, Dressler M, Lange V, Loermann P, Wolff S, Schmidt U, Lippert H, Manger T; Obesity Surgery Working Group, Competence Network Obesity: Are there gender-specific aspects of sleeve gastrectomy - data analysis from the quality assurance study of surgical treatment of obesity in Germany. Obes Surg 2012;22:1214-1219.
17 DeMaria EJ, Pate V, Warthen M, Winegar DA: Baseline data from American Society for Metabolic and Bariatric Surgery-designated Bariatric Surgery Centers of Excellence using the Bariatric Outcomes Longitudinal Database. Surg Obes Relat Dis 2010;6:347-355.

18 Tymitz K, Kerlakian G, Engel A, Bollmer C: Gender differences in early outcomes following handassisted laparoscopic Roux-en-Y gastric bypass surgery: gender differences in bariatric surgery. Obes Surg 2007;17:1588-1591.

19 Stroh C, Groh C, Weiner R, Ludwig K, Wolff S, Kabelitz M, Manger T; Obesity Surgery Working Group, Competence Network Obesity: Are there gender-specific aspects of gastric banding? Data analysis from the quality assurance study of the surgical treatment of obesity in Germany. Obes Surg 2013;23:1783-1789.
20 Livingston EH, Huerta S, Arthur D, Lee S, De Shields S, Heber D: Male gender is a predictor of morbidity and age a predictor of mortality for patients undergoing gastric bypass surgery. Ann Surg 2002;236:576-582.

21 Morais AA, Faintuch J, Leal AA, Noe JA, Bertollo DM, Morais RC, Cabrini D: Inflammation and biochemical features of bariatric candidates: does gender matter? Obes Surg 2011;21:71-77.

22 Carbonell AM, Lincourt AE, Matthews BD, Kercher KW, Sing RF, Heniford BT: National study of the effect of patient and hospital characteristics on bariatric surgery outcomes. Am Surg 2005;71:308-314. 